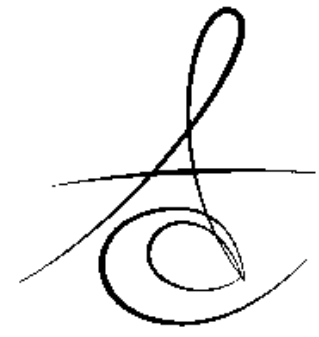

Makale Kodu/Article code: 2385

Makale Gönderilme tarihi: 24.08.2015

Kabul Tarihi: 30.09.2015

\section{PERİFERİAL ODONTOJENİK FİBROMA: NADİR BİR OLGU}

\section{PERIPHERAL ODONTOGENIC FIBROMA: AN UNUSUAL CASE}

\author{
Yrd. Doç Dr. Mükerrem HATİPoĞLU* Prof. Dr. Sinan TOZoĞLU ** \\ Dt. Zeliha AYTEKİN* \\ Doç. Dr. İrem Hicran ÖZBUDAK ${ }^{* * *}$ \\ Uzm. Havva TORU***
}

\section{öz}

Periferal odontojenik fibroma (POF) değişik miktarlarda odontojenik epitel ve kısmen olgun kollojenöz fibröz doku içermesiyle karekterize fibroblastik orjinli benign odontojenik neoplazmdır. Lezyonlar konservatif cerrahi eksizyonla tedavi edilir. Bununla birlikte tekrar oluşma potansiyeliyle dikkate alınır. Bu makalede periferal odontojenik fibroma olgusu takdim edilmekte ve doğru tanı ve hasta

Anahtar Kelimeler: Periferial Odontojenik Fibroma, Benign Neoplazm, Periodontal Cerrahi takibinin önemi vurgulamaktadır.

\section{ABSTRACT}

Peripheral odontogenic fibroma (POF) is a benign odontogenic neoplasm of fibroblastic origin characterized by relatively mature collagenous fibrous tissue and varying amounts of odontogenic epithelium. The lesions are treated by conservative surgical excision. However, it is considered to be with a potential to recur. This paper presents a peripheral odontogenic fibroma case report and emphasizes the accurate diagnosis and importance of patient follow-up.

Keywords: Peripheral Odontogenic Fibroma, Benign Neoplazm, Periodontal Surgery

mevcut akut veya kronik herhangi bir sistemik hastalı̆ı olmadığı ve düzenli veya son zamanlarda herhangi bir ilaç tedavisi görmediği anlaşıldı.

Hastanın radyolojik muayenesinde tüm dişlerin fından fibroblast kaynaklı nadir görülen bening odontojenik bir lezyon olarak kabul edilmiştir. ${ }^{1}$ POF daha çok hayatın 2. dekatında kadınlarda ve mandibular posterior bölgede görülür. ${ }^{2}$ POF klinik olarak genellikle çevresindeki yumuşak dokuyla aynı renkte yavaş büyüme eğiliminde, ülsere olmayan, asemptomatik, gingivaya bağlı ekzofilik saplı veya yapışık bir lezyondur. ${ }^{3}$ Histolojik olarak POF epitel ile ilişkili ya kalsifikasyon ya da dentin-sement benzeri materyalle karakterize bir yapı sergiler. Bunlar genellikle küçük, yaklaşık 1-2 cm çapa sahiptir. ${ }^{4}$ Enükleasyon ve küretaj sonrası nüks ettiği yönünde veriler vardır. ${ }^{5}$

\section{OLGU SUNUMU}

Otuzsekiz yaşında olan kadın hasta dişetlerinde büyümeler, kanama, ağız kokusu ve ağrı şikayetleri ile Akdeniz Üniversitesi Diş Hekimliği Fakültesi Periodontoloji Kliniği'ne başvurdu. Hastanın anamnezinden Hastaya yapılan dental muayenede hastanın hem mandibular hem de maksiller yapışık ve serbest dişeti bölgesinde, dişler çevresinde ödematöz, yüzeyden kabarık, saplı veya sapsız, eritematöz dişeti büyümeleri gözlendi (Resim 1). Hasta anamnezde, büyümelerin ilk olarak bir yıl önce ağızda olan bir köprü protezin etrafında başladığı ve köprü söküldükten sonra diğer bölgelerde de büyümeler oluştuğu bilgisini verdi.

Büyümeler ön bölgede yüzeyden çok kabarık değildi ancak arka bölgelerde çapı yaklaşık 1 cm'ye ulaşan iltihabi diffüz, yüzeyden kabarık, saplı nodüler tarzda görünüme sahipti. Hastada ciddi ağız kokusu vardı. Yapılan sondlamada yaygın periodontal cepler tespit edildi ve tüm bölgelerde iltihabın varlığına işaret eden kanama ve ciddi mikrobiyal dental plak birikimi mevcuttu.

${ }^{*}$ Akdeniz Üniversitesi Diş Hekimliği Fakültesi Periodontoloji AD

**Akdeniz Üniversitesi Diş Hekimliği Fakültesi Ağız, Diş ve Çene Cerrahisi AD

${ }^{* * *}$ Akdeniz ÏIniversitesi Tın Fakïltesi Tıbhi Patoloii AD 


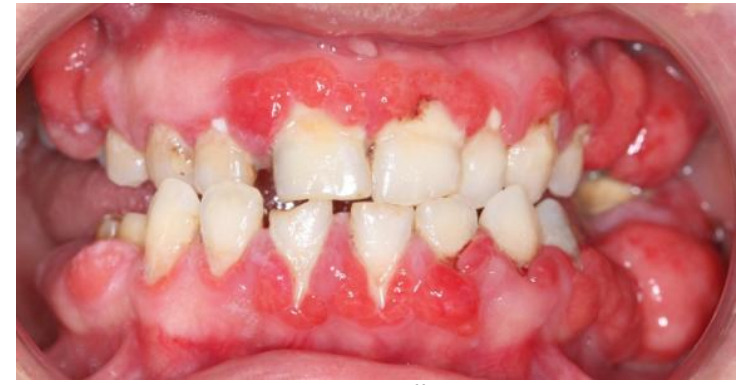

Resim 1. Hastanın tedavi öncesi ağız içi görüntüsü

Hastaya ilk seansta detertraj işlemi uygulandı. Oral hijyeni çok zayıf olan hastaya oral hijyen eğitimi verildi. Hasta sigara kullanmaktaydı ve sigarayı azaltması yönünde telkinde bulunuldu. Hastaya sık aralıklarla randevu verilerek küretaj işlemi uygulandı. Sonrasında hastanın mukogingival bölgesindeki yüzeyden kabarık büyümeden biyopsi alınarak histopatolojik inceleme amacıyla Akdeniz Üniversitesi Tıp Fakültesi Tıbbi Pataloji Anabilim Dalı'na gönderildi.

Hastanın her bir yarım çenesine farklı seanslarda gingivektomi ve gingivoplasti işlemleri uygulandı. Her gingivektomi işlemi sonrası hastaya $\mathrm{CHX}$ gargara ve antimikrobiyaller reçete edildi. Alt çene sol ikinci büyük azı dişi ileri derecede mobil olduğu için çekildi. Çekim sırasında diş etrafındaki dişeti dokusuda dişle birlikte eksize edildi (Resim 2).

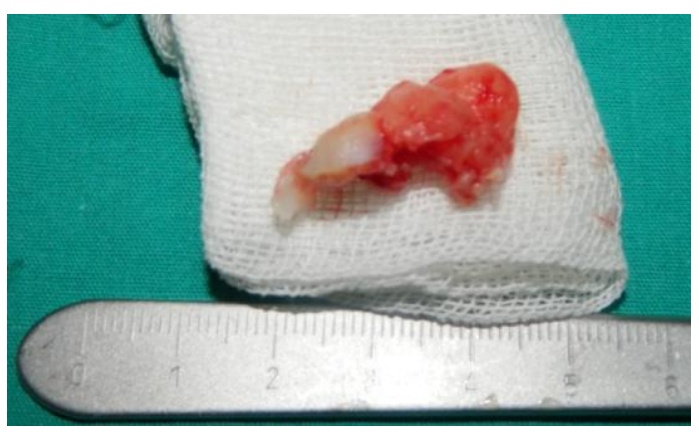

Resim 2. Operasyon sırasında alt çene sol arka bölgeden alınan tümöral büyüme

Yapılan histopatolojik incelemede yüzeyde yer yer ülsere ve rejeneratif değişiklikler gösteren çok katlı yassı epitel, epitel altında fibroblast benzeri iğsi hücre proliferasyonu ile karakterize sellüler fibröz nodül izlendi. Dağınık, periferde palizatlanma gösteren, bazıları berrak sitoplazmaya sahip odontojenik epitel gözlendi. Kollajenize stroma içinde 2 alanda kalsifiye kemik oluşumu görüldü. Mevcut klinik ve histopatolojik bulgularla olgu 'Periferik Odontojenik Fibrom' olarak değerlendirildi (Resim 3, Resim 4, Resim 5)

Yapılan tedaviler neticesinde hastadaki dişeti büyümeleri büyük oranda ekarte edildi (Resim 6). Ancak tedaviden yaklaşık 1 ay sonra hem maksiller hem de mandibular santral ve lateral kesici dişlerin fasial yüzündeki dişeti bölgesinde rekürrens gözlemlendi. Bu bölgelerde gingivektomi ve gingivoplasti işlemi tekrarlandı ve hasta periyodik takibe alındı. Bir yıllık takibinde yeni bir nükse rastlanılmadı.

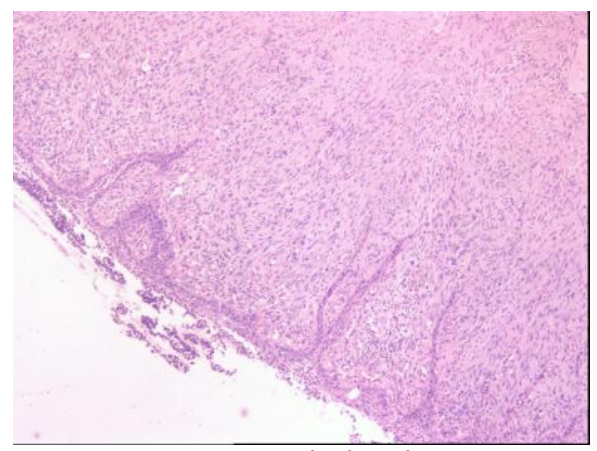

Resim 3. Yüzey epitelinde ülserasyon ve rejenerasyonla karakterize sellular fibröz nodül görüntüsü

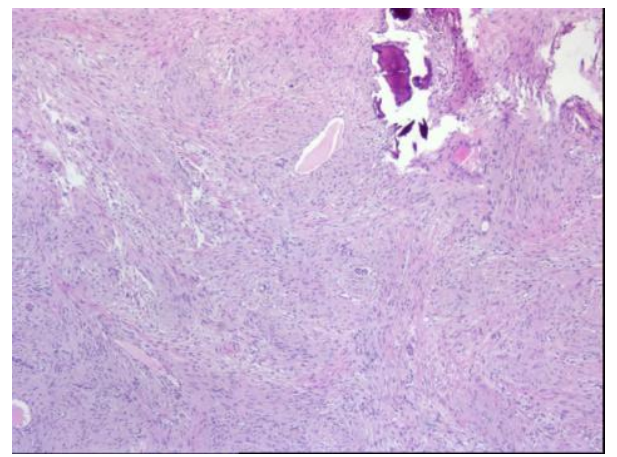

Resim 4. Kalsifikasyon ve odontojenik epitel adaları da içeren fibroblast benzeri iğsi hücrelerin proliferasyon görüntüsü

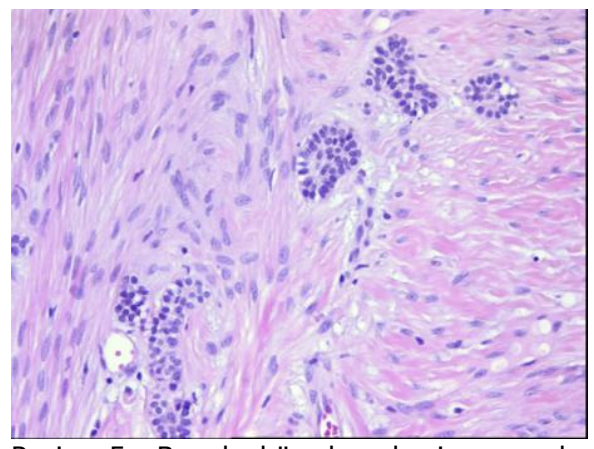

Resim 5. Berrak hücreler de içeren odontojenik epitel görüntüsü 


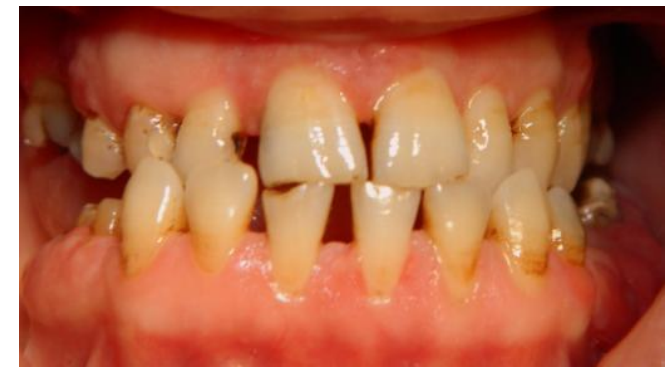

Resim 6. Hastanın tedavi sonrası ağız içi görünümü

\section{TARTIŞMA}

WHO tarafından "Odontojenik Fibrom" santral veya ekstraosseöz yerleşimli, çeşitli miktarlarda odontojenik epitel ve matür kollojenöz fibröz doku içeren fibroblast orijinli bening odontojenik neoplazm olarak tanımlanmıştır. ${ }^{6}$ 1982'de Gardner ${ }^{7}$ POF'u santral odontojenik fibromun ekstraosseöz bir formu olarak tarif etmiştir.

Periferial şişliklerin diferansiyel diagnozu sıklıkla piyojenik gronüloma, periferial ossifaying fibrom, periferial dev hücreli gronülom, periferial ameloblastoma, parulis, ve fibroma ile yapılır. ${ }^{8}$ Ayırıc tanıda histopatolojik özellikler dikkate alınarak kesin tanı konulur.

POF'un histolojik olarak periferial ossifying fibromdan kesin olarak ayırt edilmesi gerekir. İkisi arasındaki histolojik olarak ana fark POF içindeki odontojenik epitel varlığı ve periferial ossifying fibrom içindeki displastik dentin varlığıdır. ${ }^{10}$ Klinik görünüşleri benzer olabilmesine rağmen ossifying fibrom POF'un aksine gingivanın reaktif fibröz lezyonudur. ${ }^{11}$ Lin ve ark. ${ }^{15}$ yaptıkları çalışmada örneklerin tamamında epitel ile birlikte dentin-sement benzeri kalsifikasyon göstermişlerdir. Olgumuzun histopatolojisinde de bu detaylar dikkate alınarak tanı konulmuştur.

POF ile ilgili yaptığımız literatür taramasında bir çok çalışmadaki verilerin olgumuzla örtüştüğünü tespit ettik. Garcia ve ark. ${ }^{4} 17$ hastayı içeren çalışmalarında bu lezyonun \% 88.2 gibi yüksek bir oranda kadınlarda ve \%76.4 oranında hayatın 2. ila 4 . dekatında olduğunu, çoğunlukla mandibulada yer aldığını öne sürmüşlerdir. Daley ve Wysocki ${ }^{5} 36$ olgudan oluşan çalışmalarında geniş bir yaş aralığını incelemişlerdir. Kadınlarda insidansın yüksek olduğunu ve mandibulada maksillaya göre ufak bir oranda daha sık olduğunu bildirmişlerdir. Siar ve ark. ${ }^{12} 46$ olgudan oluşan çalışmalarında, kadınlarda nispeten daha sık görüldüğünü (kadın / erkek 1.3/ 1), hayatın 2. dekatında pik yaptığını ve önemsenmeyecek oranda mandibulada daha sık olduğunu bildirmişlerdir. Buchner ve ark. ${ }^{13}$ da yine kadınlarda kısmen daha sık görüldüğünü ve 12 ila 84 gibi geniş bir yaş aralığında hayatın 2-4 dekatında daha sık ve mandibular lokasyonun daha fazla olduğunu bildirmişlerdir.

Diğer taraftan Kenney ve ark. $^{2}$ yaptıkları 13 olgudan oluşan çalışmada hayatın 3-4 dekatında daha sık, çoğunlukla mandibulada oluştuğunu bildirmekle birlikte, diğer araştırmalardan farklı olarak erkeklerde nispeten daha sık olduğunu rapor etmişlerdir. Slabbert ve Altini $^{14}$ de erkeklerde prevelansın daha yüksek olduğunu, 11-76 yaş aralığında hayatın 3. dekatında ve kısmen mandibulada daha sık rastlanıldığını bildirmişlerdir. Olgumuzda da 38 yaşındaki bayan hastanın her iki çenesinde lezyon yer almış olmakla birlikte mandibulada daha şiddetli görüldüğü tespit edilmiştir.

POF' $^{\prime}$ un tedavisinden sonra rekürrens oranı genelde düşük bulunmuştur. ${ }^{2} \mathrm{Bu}$ nedenle tedavide basit cerrahi eksizyon tercih edilmektedir. ${ }^{15}$ Kenney ve $a^{2}{ }^{2}$ sadece bir olguda rekürrens gözlemlemişlerdir. Bununla birlikte Daley ve Wysocki 30 olgunun 7'sinde rekürrens rapor etmişlerdir. Garcia ve ark. ${ }^{4}$ ise 17 olgunun 3'ünde nüks bildirmişlerdir. Ritwik ve Brannon ${ }^{16}$ 151 olgudan oluşan çalışmalarında \%50 oranında rekürrens rapor etmişlerdir ve rekürrensin ne lezyonun büyüklüğüyle ne de hastanın ırkıyla ilişkili olmadığını bildirmişlerdir. Çalışmamızda yapılan tedavilerden 1 ay sonra nüks görülmüştür. Rekürrensin yüzey epitelinin bazal hücre tabakasında tomurcuklanmanın histolojik varlığı ile ilişkili olduğu ve bu nedenle histopatolojik incelemenin gerekliliği ile birlikte düşük rekürrensin ise odontojenik epitel artıklarının arasında kalsifikasyon varlığıyla ilişkili olduğu düşünülmektedir. ${ }^{16,17}$ Maligniteye dönüşme meyili olmadığından, kapsamlı radikal rezeksiyon tedavilerinin hastanın yaşam kalitesini düşürebileceğinden dolayı çalışmamızda da basit cerrahi eksizyon tercih edilmiştir. Bununla birlikte POF'un tedavisinden sonra hastaların nüks olasılığı nedeni ile mutlaka takibi yapılmalıdır.

\section{SONUÇ}

Dişetinde görülen lezyonların birçoğu klinik görünüş açısından birbirine benzemektedir. Bu konuda yapılan klinik, radyolojik tetkikler diferansiyel diagnoz-

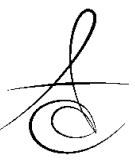


da yeterli olmayabilir. Kesin tanı için lezyonların histolojik olarak incelenmeleri gereklidir. Dişetinde nadir görülen, bening bir tümör olan POF'un tedavisi basit eksizyondur. Nüks etme eğilimi olan bir lezyon olduğu için tedavi sonrası düzenli kontrolleri yapılmalıdır.

\section{KAYNAKLAR}

1. Philipsen HP RP, Sciubba JJ, et al. Odontogenic, tumors. In: Barnes L EJ, Reichart $P$, et $\mathrm{al}_{\text {, }}$ eds. World Health Organization Classification of Tumors. Pathology and Genetics of Head and Neck Tumors., IARC Press, eds., In: Lyon: 2005; 102-5

2. Kenney JN, Kaugars GE, Abbey LM. Comparison between the peripheral ossifying fibroma and peripheral odontogenic fibroma. J Oral Maxillofac Surg.: official journal of the American Association of Oral and Maxillofacial Surgeons 1989;47:378-82.

3. Buchner A, Ficarra G, Hansen LS. Peripheral odontogenic fibromaOral Surg Oral Med Oral Pathol 1987;64:432-8.

4. Garcia BG, Johann AC, da Silveira-Junior JB, Aguiar MC, Mesquita RA. Retrospective analysis of peripheral odontogenic fibroma (WHO-type) in Brazilians. Minerva Stomatol 2007;56:115-9.

5. Daley TD, Wysocki GP. Peripheral odontogenic fibroma. Oral Surg Oral Med Oral Pathol 1994; 78:329-36.

6. Weber A, van Heerden WF, Ligthelm AJ, Raubenheimer EJ. Diffuse peripheral odontogenic fibroma: report of 3 cases. J Oral Pathol Med.: official publication of the International Association of Oral Pathologists and the American Academy of Oral Pathology 1992;21:82-84.

7. Gardner DG. The peripheral odontogenic fibroma: an attempt at clarification. Oral Surg Oral Med Oral Pathol 1982;54:40-8.

8. Shafer WG HM, Levy BM. Text Book of Oral Pathology. In: 5th ed. Reed Elsevier India Private Limited $2006: 41$.

9. Posivillo D BM, Foster M. Dental Oral and Maxillofacial Surgery.. In: W Heinemann Medical Books; London 1986:168-72.

10. Buchner A. Peripheral odontogenic fibroma. Report of 5 cases. J Craniomaxillofac Surg. official publication of the European Association for CranioMaxillo-Facial Surgery 1989;17:134-8.
11. Zain RB, Fei YJ. Fibrous lesions of the gingiva: a histopathologic analysis of 204 cases. Oral Surg Oral Med Oral Pathol 1990;70:466-70.

12. Siar $\mathrm{CH}, \mathrm{Ng} \mathrm{KH}$. Clinicopathological study of peripheral odontogenic fibromas (WHO-type) in Malaysians (1967-95). Br J Oral Maxillofac Surg 2000; 38:19-22.

13. Buchner A, Merrell PW, Carpenter WM. Relative frequency of peripheral odontogenic tumors: a study of 45 new cases and comparison with studies from the literature. J Oral Pathol Med: official publication of the International Association of Oral Pathologists and the American Academy of Oral Pathology 2006; 35:385-91.

14. de Villiers Slabbert $H$, Altini $M$. Peripheral odontogenic fibroma: a clinicopathologic study. Oral Surg Oral Med Oral Pathol 1991;72:86-90.

15. Lin CT, Chuang FH, Chen JH, Chen CM, Chen YK. Peripheral odontogenic fibroma in a Taiwan chinese population: a retrospective analysis. Kaohsiung J Med Sci 2008;24:415-21.

16. Ritwik P, Brannon RB. Peripheral odontogenic fibroma: a clinicopathologic study of 151 cases and review of the literature with special emphasis on recurrence. Oral Surg Oral Med Oral Pathol Oral Radiol Endod 2010; 110:357-63.

17. Ünür $M, A K$ G. Periferik fibroma ( 9 olgu nedeniyle). Atatürk Üniv Diş Hek Fak Derg 1997; 7: 81-3.

\author{
Yazışma Adresi \\ Yrd. Doç. Dr. Mükerrem Hatipoğlu \\ Akdeniz Üniversitesi, \\ Diş Hekimliği Fakültesi, \\ Periodontoloji Anabilim Dalı, \\ Antalya, Türkiye. \\ Faks: +902423106967 \\ Telefon: +90 2422274400 \\ E-posta: mukerremhatipoglu@hotmail.com
}

